\title{
Modelling trust formation in health information contexts
}

Journal of Information Science

$1-16$

(C) The Author(s) 2015

Reprints and permissions:

sagepub.co.uk/journalsPermissions.nav DOI: $10.1177 / 0165551510000000$ jis.sagepub.com

@AGE

\section{Frances Johnson}

Department of Languages, Information \& Communications, Manchester Metropolitan University

\section{Jennifer Rowley}

Department of Languages, Information \& Communications, Manchester Metropolitan University

\section{Laura Sbaffi}

Department of Languages, Information \& Communications, Manchester Metropolitan University

\begin{abstract}
This study explores trust formation in the context of health information. Trust as an interpersonal notion, when formed in a vulnerable state, is a response or belief about how the trusted will behave towards the trustor. This study focuses on the process of assessing the trustworthiness of information, in a dependency state of information need, through the identification of the many factors influencing this assessment. A set of propositions are developed to suggest the criteria by which trustworthiness is assessed as well as the factors that influence these judgements. The proposed model is tested in a large scale survey using a trust inventory with factor analysis to explore the constructs of trust formation. Structural equation modelling is used to explore the relationship among the identified criteria and their influencing factors. The resulting framework contributes to the understanding of trust formation in digital information contexts on the criteria of usefulness and credibility and further research into the influencing factors is recommended.
\end{abstract}

\section{Keywords}

Trust formation. Information Evaluation. Relevance Judgements. Information Seeking Behaviour. Health information seeking

\section{Introduction}

On what basis do we trust information found in health information seeking contexts? Kohn states that "[m]aking sense of trust requires deciding what trust is" but that there exists a community of meanings labelled as 'trust' (Kohn [1]). Trust is "complex and multidimensional" (Chopra \& Wallace [2]), can "have various meanings" and is "viewed differently" in different situations and contexts (Shekorpour \& Katebi [3]). When trust is formed in a dependency state, for example to resolve a query on a health issue, as a judgement it is likely to be affected by many different attributes of the information and its delivery. The judgement may also be moderated by the context in which the information is sought. In this study, it is proposed that the key to studying trust is to identify the criteria on which trust judgements are formed and identify, in turn, the factors that influence these criteria. That is, according to Yi et al. [4], to disentangle the criteria used to evaluate the information in forming trust from the factors that influence them. Previous studies of trust have identified a comprehensive list of the many factors that might influence trust formation. Disentangling and thus identifying the criteria and modelling the relationship of these and the influencing factors aims to develop a measurement scale for the study of trust in a variety of digital information contexts.

This study aims to contribute to understanding 'trust' as a central concept in the assessment of health information encountered in digital information contexts. The approach taken departs from previous research which, in general, adopts exploratory methods to identify the core factors as having major influence on formation of trust, and takes a positivist perspective to identify the relative importance and the relationships between the factors that are identified in previous research. Informed by a set of propositions, a psychometric questionnaire is used to identify the evaluative judgements that young people (students) employ in considering the trustworthiness of health information found on the

\section{Corresponding author:}

Frances Johnson, Department of Languages, Information \& Communications, Manchester Metropolitan University, Geoffrey Manton Building,

Manchester, MI5 6LL, UK.

E-Mail: F.Johnson@mmu.ac.uk 
web. More specifically, this study adopts a critical incident approach to identify the core criteria and factors when asked to recall which were most important in assessing the trustworthiness of the information. The critical incident approach has been used extensively in information seeking research as it has the advantage that the incident is relevant to the searcher, and is therefore closer to 'real life' than an experimental setting, and it also facilitates the collection of a larger dataset, thereby permitting more rigorous quantitative analysis. In this study the responses to the questionnaire regarding the assessment of information were analysed to identify the core criteria on which trust is formed and the relationship among the influencing factors relating to the document attributes and user perceptions of the information. The resulting framework contributes to the understanding of trust formation in digital information contexts on the criteria of usefulness and credibility and further research into the influencing factors is recommended. In the following sections the literature is reviewed to define trust and to identify the core propositions of trust. Identifying the core factors leads to the research model and the development of the measurement scale. The empirical study to test the scale and the proposed two-factor model on the criteria of usefulness and credibility is presented from the data analysis. The limitations of the study are discussed and the further development and use of the model is identified for the study of the formation of trust in digital information contexts.

\section{Review of Related Work}

\section{I. Trust as an attitude}

Trust in electronic environments has been variously studied (Chopra \& Wallace [2]; Ivanov et al. [5]; Kelton et al. [6]; Shekapour \& Ketebi [3]; Belanger \& Carter [7]) and as the Internet becomes more pervasive in everyday life, the issue of information found online and how much to trust it becomes an increasing concern (Kelton et al. [6]). Chopra and Wallace [2] comment that trust in information is a "social attitude" which tends to relate to a particular "technological artefact", for instance, information found on the Internet. As an attitude, trust may be understood to be a belief that what others are saying or doing is correct, a "general expectancy held by an individual that the word, promise oral or written statement of another individual or group can be relied upon" (Rotter [8]). As a cognitive issue, trust appears as a reliance on some sort of "mutual interest" or a "want' to maintain the relationship (Hardin [9]). In the context of online information, the user (the 'trustor') looking for or wanting information has a particular need to fulfil, and the information (in which the user places trust) possesses the potential to satisfy this need. This state of dependence between the 'trustor' and the 'trustee' satisfies the precondition that Chopra and Wallace [2] propose is required for trust. They further outline this precondition for trust in stating that acting on this dependence must entail a risk with potential uncertainty about the outcome and a vulnerability to the potential loss from an undesirable outcome. This is to say that, given these preconditions, we can assume that trust is likely to be formed in the context of looking for and finding information on the web in response to some health issue, concern or need. Furthermore, from an analysis of commonalities in a set of definitions of trust, Rowley and Johnson [10] have suggested that the positive belief formed must be verifiable and will lead to a state of 'intention to use'. Thus the users' judgement of the trustworthiness of the information, in a state of dependency and intention to use, is central to understanding the effective provision and use of digital information. Not surprisingly then many studies have used 'trust' as a measure or metric to increase understanding of information use and behaviour in various contexts.

This basis for this study identifies trust to be a multidimensional concept that is formed and is dependent on the trustor's particular situation or information need. In the consideration of trust as multidimensional, cognitive and seemingly dynamic concept we pose the question - what are the constructs of this judgement and what are the factors that influence or affect such a judgement? Thus the aim of this study, is not to measure trust, but to identify its constructs to propose a model of its formation for use in further research.

\subsection{Factors influencing trust}

Extant research has, in general, adopted exploratory methods to identify the many core factors as having major influence on formation of trust. Gouge and Gilson [11] review the qualitative research that explores and identifies the attributes that promote perceptions of trustworthiness, in interpersonal trust and in the health sector, such as a person's perceived competency or honesty. In digital information trust contexts, various characteristics and attributes of the information have been identified as promoting trust formation. Corritore et al. [12] has shown that trust in health information websites was significantly explained by users' perceptions of website credibility, ease of use and risk. Ye [13] explored 
the extent of correlation of consumer trust in online health information with income, education, health status, engagement in social network sites, ease of location of information, understandability, and trust in health information through other media (doctors, family and friends, print media). Sillence et al. [14] found that, in the context of health websites, the top five trust markers were: the site was easy to use, the advice came from a knowledgeable source, the advice appeared to be prepared by an expert, the advice appeared to be impartial and independent, and the reasoning behind the advice was explained. They also recognised that the situation was dynamic, and affected by the source available and user experience. In another diary-based study, Sillence et al. [15] found that the factors contributing to the selection and trust of web sites can be divided into design factors (clear layout, good navigation aids, interactive features) and content factors (e.g. informative content, unbiased information, clear, simple language). In their guidance on how to investigate (specifically interpersonal) trust, Gouge and Gilson [11] draw attention to the value of quantitative inquiry to test the identified factors influencing trust and to understand trust building over time and its dependence on context, particular (health) issues or individuals involved (Mechanic \& Meyer [16]). However, despite the acknowledged importance of trust in online information environments, researchers have wrestled with the development of adequate measurement scales. Wang and Emurian [17] point out considerable variability in the way in which researchers operationalise the concept and the way in which they explore the relationship between trust and its antecedents and consequents. They go on to suggest that trust is:

... often conceptualised by researchers according to the features of the particular context' and that 'it is often used interchangeably with related concepts such as credibility, reliability, or confidence (p.108).

With the exception of the respective18-item and 24-item scales used by Briggs et al. [18] and Sillence et al. [15] to measure trust in the context of health information, measurement scales of trust in online information are generally relatively simple and often focus on specific cues of health website trustworthiness, rather than taking a broader conceptual approach to trust (Corritore et al. [12]). As a result, previous research appears to suggest the cues or the characteristics of information (or a source) invoke some placement of trust, but fail to develop insight into the process of trust formation. As O'Neill [19] explains, trust is formed in the process of assessing trustworthiness, suggesting that it is the judgements made on some criteria (for example, on the information attribute of credibility) that promotes the formation of trust. A few studies have sought to resolve this by proposing theoretical frameworks (e.g. Kelton et al. [6]; Lucassen \& Schragen [20]; Metzger [21]; Wang \& Emurian, [17]; Wather \& Burkell [22]). Whilst these attempt to build a model of the relationships between trust and its preceding judgements in various contexts, there is considerable diversity in the relationships proposed and tested. For example, Cugelman et al. [23] examined the dimensions of website credibility (identified as expertise, visual appeal, and trustworthiness), with active trust. Shen et al. [24] studied trust in the context of student use of Wikipedia, and built a model with sources credibility and information quality (including completeness and format) as antecedents to information usefulness, which in turn was an antecedent to trust in Wikipedia and information adoption. Harris et al. [25] proposed and tested a predictive model of trust in internetbased health information and advice, with information quality, personalisation, impartiality and credible design as antecedents to trust, and corroboration and threat as mediating variable. Wathen and Burkell [22] differentiate between evaluation of surface characteristics, which includes appearance/presentation, usability/interface design, and organisation of information, and evaluation of message credibility, which includes source and message components. Lucassen and Schragen [20] propose and test the 3-S model of information trust, which suggests that trust formation is influenced by information characteristics, and user characteristics (domain expertise, information skills, and source experience). Their study suggests that these user characteristics lead to different features of the information being used in trust judgements in different contexts.

The lack of consensus on how trust is conceptualised presents a potential for confusion in any attempt to identify the attributes of the information used in assessing its trustworthiness. This may arise when, for example, credibility and information quality are both identified as factors that promote the formation of trust. This may be the case but, as a model fails to identify any relationship between the judgement formed on the information credibility, as an antecedent to trust, and the assessment of the information quality. That is to say, information quality as an attribute would not simply invoke trust, but may however influence the judgement of trustworthiness. Put simply, assessing trustworthiness requires some 'action' or judgement from the trustor and to understand the trust formation in digital information, and its dependency on contexts, it is necessary to identify the core criteria as the antecedents of trust and to distinguish the attributes or inherent properties of the information that may influence the judgement. This identifies a possible shortcoming in these models that may appear to lack a consensus on how trust is conceptualised, but also, it may be 
suggested that they fail to reflect how users might think about trust which according to Fergie et al. [26] Sillence et al. [27] which often involves rapid and heuristic based judgements.

\section{Research Model}

\section{I. Introduction}

Key questions remain in the endeavour to understand trust in specific contexts. In particular, what are the core constructs of the trust judgement when formed in the context of digital information? In order to make sense of trust in digital information section 3.2 presents a set of propositions deduced from previous research on the judgements made in information seeking contexts. Focusing on the process of trust formation and on the assessment of information trustworthiness, the aim is to identify the factors influencing trust, and crucially, what are the core criteria on which trust is formed to distinguish these judgements from their influencing factors or determinants. This conceptualises trust formation in digital information as a process, involving the user in making judgements and dependent on the context of the users' information need. This is based upon, and is further explained by drawing a comparison with longstanding research into the concept of relevance as a dynamic judgement in information science (Saracevic [28]; Borlund [29]). Relevance is conceptualised as a subjective judgement of the information's 'topicality' as perceived by the user in relation to an information need, and its 'usefulness' with regards to its actual use in directly resolving the given problem. The judgement as a continuum can assume topicality, an attribute of the document, as a basic requirement of a users' judgement of a document as relevant. Further along in a continuum of relevance, the user may be expected to make a judgement of the documents' usefulness in relation to the problem in hand. Where this distinction is helpful is in its identification of the core criteria for relevance judgements, such as usefulness, utility, pertinence as well as the identification of the independent variables such as aspects of the document, for example its topicality, style and novelty in providing new information to the user. Thus the perceived attributes of the document (or its information) contribute to the users' overall relevance evaluation and this judgement is formed on the criteria of usefulness (and its possible surrogates such as pertinence) as the dependent variable. As a framework for the study of trust, the information characteristics and the criteria for the formation of trust are distinguished and treated at different levels. This framework can then be further developed by distinguishing the types of influences and modelling their relations to the criteria used in trust formation. Drawing on the Elaboration Likelihood Model (ELM) which has been used to explain individual's changes to the credibility assessment as they encounter specifically, persuasive communication (Rieh \& Hilligross [30]; Sundar [31]), an important distinction is made between content and otherwise peripheral cues (Cacioppo \& Petty[32]). The content of the argument quality may be one way to influence an individual's attitude to a persuasive message. ELM states that, equally so, the peripheral clues, such as source reputation, may also be used to influence attitude. Both Cacioppo and Petty [32] and Sundar [31] have suggested that individuals may base their judgement of a message, not on its content but, on peripheral cues when the motivation to engage in the mental effort in analysing a message based on content is missing or lacking. As the factors that have been previously identified as influencing or even determining trust formation range from content to others that may be regarded as 'peripheral', such as ease of use, it is important that any model of trust formation allows for this distinction to be made across the influencing factors. In particular, as trust is identified as a dynamic judgement made in context of an information need the ELM implies that this context might determine the type of factors used in trust.

To propose the model of trust, the following propositions are presented for the development of a multi item scale to identify the criteria and influencing factors (both content and peripheral) in trust formation in information 'use' contexts.

\subsection{Key propositions}

P1 - Assessing information credibility is an antecedent to trust

One of the fundamental conceptual debates in relation to trust in digital information is on the relationship between trust and credibility. The assertion regarding the interchangeable use of trust and credibility as if they are the same thing was made by Wang and Emurian [17] and Tseng and Fogg [33], and there is plenty of evidence of this in key empirical studies in the field; for example, Rieh and Hilligoss [30] and Hargittai et al. [34] use the terms interchangeably, whilst 
Sillence et al. [14] do not define either trust or credibility. Other researchers show trust or trustworthiness as an element of credibility (Cugelman et al. [23]; Wathen \& Burkell [22]), whereas others view online trust as a complex construct that includes credibility (Shankar et al. [35]); Tseng \& Fogg [33]) recognised this dilemma, and proposed the following distinction:

Trust indicates a positive belief about the perceived reliability of, dependability of, and confidence in a person, object or process. Credibility is synonymous with believability (p.41).

However, Kelton et al. [6] dispute Tseng and Fogg's definitions of trust and credibility, and argue that their definition of trust is too narrow - they claim that the relationship between trust and credibility is an open area for further research, and generally propose that there is need for more in-depth exploration of the components of the trust concept. Here we argue first and foremost that it is important to take a position on the relationship between trust and credibility, and that whilst, on occasions, it may be appropriate to use them interchangeably, this use should be informed and deliberate. In proposing the framework for the study of trust we take the position that trust is the super-ordinate concept and that it subsumes credibility.

P2 - Assessing information usefulness is an antecedent to trust

In a similar vein we propose that trust subsumes usefulness as a core criteria used in the assessment of the information sought in some dependency state. The concept 'relevance' from traditional information retrieval theory is generally defined as the extent to which a document or piece of information solves a problem or satisfies an information need. In systems terms, relevance could be viewed as the match between a set of documents and the user's query. However, other types of relevance are more subjective and are more likely to be important to and employed by users. These include relevance to a subject (topical relevance), relevance to the user's existing state of knowledge (cognitive relevance) and, relevance to a task or problem (situational relevance). A distinction is usually made between subject and situation relevance - specifically that the 'aboutness' of a document in relation to some information need is subject relevance and the usefulness or utility of the information is with regards to the information need or task in hand (Borland [29]). Simply put, the document may be topically relevant, but irrelevant with regards to situation relevance if it fails to contribute to the problem or task in hand. The centrality of the judgement of 'usefulness' is confirmed for example in Lim's [36] exploration of responses to a range of anticipated outcomes (expectations) as factors related to information use. A number of factors including past experience, disposition to information, information utility and verbal persuasion were tested on a series of statements such as "I will find useful information" ([36, p 2192]). The findings indicated that information utility will be a core factor related to the outcome expectations and use of the information. However, Hertzum et al. [37] suggest that relevance, even taking into account different types of relevance, is not the only factor that users use when assessing documents. She proposes two other key factors are trust, and the 'least-effort principle'. We propose that trust subsumes usefulness along with credibility judgements in the sense that these are preconditions made in the process of trust formation and with respect to the information need context. The premise that trust formation in digital information is based on the judgements of the credibility and usefulness of the information allow for the possibility that a variety of factors will influence these judgements and the importance of which is likely to be determined by the context. These further factors that may relate to the core criteria are identified in propositions $\mathrm{P} 3$ and $\mathrm{P} 4$.

\section{P3 -Perceiving information quality is pivotal to trust formation}

Chopra and Wallace [2] define users' trust in information as a social attitude towards an item where there is an expectation that the information will be reliable and valid and will be assessed on a rational basis using quality indicators such as accuracy, coverage, timeliness and depth. They suggest that trust in digital information can develop based on such indicators. Further studies of trust formation suggests that authorial authority is pivotal to trust formation in digital information with user interest in the authority associated with authorship, and indeed author names may well be recognised, or have affiliations that lend further confidence in the reliability of the digital information. The other factor, which emerges repeatedly from the empirical evidence on trust formation in digital environments and related studies, is information presentation. This is represented in slightly different ways in different studies, and, information presentation factors are more obviously evident in studies on website credibility, such as that conducted by Tseng and 
Fogg [33]. This study investigated how users evaluate the credibility of web sites in ten categories, including ecommerce, finance, search, and health; top of their list of the themes that occurred most frequently in connection with credibility judgements were: design look, information design/structure, and information focus. Similarly, in Sillence et al. [15] diary study of how patients evaluate and make use of online health information, design factors, such as clear layout, good navigation aids, and interactive features were found to contribute to the selection and trust of web sites. Rowley and Johnson [10], found that students expressed considerable interest in the structure, style and quality of writing of Wikipedia articles, and grammatical, or other editorial or proofreading oversights, and these impacted on their trust judgements.

\section{P4 - Peripheral cues influence trust formation}

Previous research into trust formation identifies a set of possible peripheral or contextual 'information' related cues that may influence trust. We tend to trust big brands and this extends to digital information contexts with respect to the information providers. Pan et al. [38] suggested that people were more likely to trust the results from Google and furthermore claimed these results to be superior. Bailey et al. [39] similarly found that when branding was removed users were unable to tell the difference in quality between the search results from two popular search engines. The influence of recommendation is also of interest as a factor employed by users to potentially reduce the complexity in decision making in uncertain situations (whether to trust information) and so used as a mechanism as such. Further influencing factors may be identified from the empirical evidence from both the trust and credibility literatures suggesting that, in digital environments, verification, or checking the information content with other sources is at the core of trust formation. In a large study of first year undergraduate students, amongst the factors that Hargittai et al. [34] identified as most important in credibility assessment were: sources for validation, authorship, and linking sites. Students in Iding et al. [40] study sought corroboration with other web sites. Rieh and Hilligoss [30], examined college students' credibility judgement in the information seeking process using an interview based study and confirmed that students certainly undertook evaluation of information, based on their current knowledge on the topic, quality control mechanism (refereeing, editing), and verification (through using multiple sources and co-referencing).

\section{P5 - Trust formation can be modelled by its core criteria and determining factors}

Our research model focuses on the process of trust formation. Previous research identifies many different factors that may influence trust. The propositions P1-P4 relate the ongoing process of trust formation as that of assessing the trustworthiness of the information and this provides a framework to identify the core criteria of the usefulness and the credibility of the information. Information quality, variously expressed as reliability, accuracy and authorial authority are pivotal factors in assessing trustworthiness as are brand, recommendation, verification and ease of access. The framework crucially distinguishes the core criteria by which information is assessed and their influences, both from the information content and peripheral cues and which may be variously applied according to different contexts and situations. In this way, trust is conceptualised as formed as a process, a series of judgements as events involving the user and modelled on the core criteria which may invoke trust which, in turn, are determined by the various factors.

\section{Methodology}

\section{I. Research design}

The empirical study adopted a quantitative, survey-based research design, in order to gather sufficient data to be able to develop measurement items and explore relationships between variables in the process of trust formation. Questionnaires were chosen to collect data as they were deemed suitable for gathering large amounts of data and collecting accurate information.

A four-sided, paper-based questionnaire was developed. The core of this questionnaire was a bank of Likert-style statements, designed to investigate respondents' perceptions of the relative importance of various aspects of web health information in their evaluation of its trustworthiness. Items (questions) to reflect the constructs for credibility, usefulness, content, authority, style, verification, brand, ease of use, recommendation were designed with a 5 point scale. Whilst these constructs may not be observed directly, they may manifest through responses to questions regarding the construct. For example, to measure the impact of 'style' we ask survey participants about the importance of the way 
that the information is structured. The inclusion of specific factors and the questions (or items) on which they are based were largely drawn from previous research, adapted from Sillence et al. [15]; Metzger [2`]; Walraven et al. [41]; Hargittai et al. [12]; Wang and Emurian [17] as shown in Table 2. This, to some extent, ensures content validity in that the items used in the survey provide representative coverage of the possible questions and reflect the possible aspects of the construct. However, since few researchers have proposed multi-item scales of trust in digital information and its associated factors, in many instances it was necessary to generate new items in pursuit of proposing and validating a new scale. For face validity the researchers discussed the phrasing of the questions and ran a pilot which led to some minor changes. Thus the aim was to include a set of items reflecting different aspects of the construct such that the responses to the items could be taken as a manifestation of the construct.

Questionnaires were distributed to students in class settings. After a brief introduction, students were invited to complete the questionnaire. Prior to responding to the Likert-style statements, respondents were asked to think about a specific instance when they had looked for health or medical information on the internet. This domain was chosen to provide a type of critical incident as it was assumed that all, at some point, will have looked up information relating to a health issue and, aided by the trust inventory, will respond to the items reflecting their responses to the underlying constructs in assessing trustworthiness. They were then invited to indicate whether their search was triggered by general interest, or because they or a member of their family had a specific complaint.

At the end of the questionnaire, respondents were asked about their disposition to trust, and their health status, before being asked to provide basic demographic data such as gender, age, course level, course subject, and, student status (UK or International). Completed questionnaires were collected immediately by the researchers.

\subsection{Participants}

Participants were third year undergraduate students on courses in Business and Sport Science at a large metropolitan university in the UK. Consistent with previous research studies on student and young people's health information seeking behaviour, and trust judgements in digital environment (e.g. Dobransky \& Hargittai, [42]; Gray et al. [43]; Hargittai et al. [34]; Menchen-Trevino \& Hargittai [44]; Walraven et al. [41]), convenience sampling was employed to maximise response rate. Most respondents were aged between 18 and 21, there is a relatively even distribution on gender, and between the main subject categories. Most participants had either a level of involvement that fell into the general interest category (41\%) or were answering in respect of their information searching with regard to a recent personal health issue with $43 \%$ most serious, $15 \%$ serious. On health status, $73.7 \%$ either agreed or strongly agreed that they were generally healthy, whilst $21.9 \%$ either agreed or strongly agreed that they had recently experienced a major health issue (Table 1).

Table I: Profile of participants.

\begin{tabular}{llrr}
\hline & & No. & $\%$ \\
\hline Gender & Male & 165 & 56.5 \\
Subject & Female & 127 & 43.5 \\
& Business & 136 & 46.6 \\
Level of involvement & Sport & 156 & 53.4 \\
& General interest & 121 & 41.4 \\
& Not serious & 126 & 43.2 \\
Health status & Serious & 45 & 15.4 \\
& Generally healthy & 215 & 73.7 \\
& Recent major issues & 64 & 21.9 \\
& Not responded & 13 & 4.4 \\
\hline
\end{tabular}




\subsection{Data Analysis}

Table 2 presents the descriptive statistics for all of the items in the measurement scale. Cronbach's alpha coefficients for all intended constructs were higher than the minimum cut-off of 0.70 (DeVellis [45]) and with the deletion of five items the coefficients ranged from 0.705 to 0.845 indicating internal consistency. The descriptive statistics show that most of the items have a mean between 3 and 4 which would indicate an upward bias in the sample. As we asked participants to respond to the questions based on information they had found in relation to some health information need we might assume a minimal rating on each of these constructs (i.e. that the information was considered to be useful and credible). Also we observe that the overall mean for all of the constructs is similar suggesting that all make a similar level of contribution to trust judgements and that there appears to be a range of factors influencing these judgements, confirming assertions that these judgements are complex. Specifically, on the basis of the means, of the intended constructs credibility (4.27), ease of use (4.24) and content (4.03) could be considered to be most important in influencing trust judgement. Recommendation (3.93) and authority (3.90) were also high and brand (3.59) is the least important. Items with the highest rating within credibility, ease of use and content were Whether I feel I can believe the information (4.42), The quality of the information (4.40), That the information was free (4.36), How easy it was to access the information (4.28), The comprehensiveness of the information (4.42) and The accuracy of the information (4.32).

Table 2: Descriptive statistics of all means and constructs.

\begin{tabular}{|c|c|c|c|c|c|}
\hline $\begin{array}{l}\text { Variable (CA } \\
\text { value) }\end{array}$ & Item & Code & $\begin{array}{l}\text { Variable } \\
\text { Mean }\end{array}$ & Mean & s.d. \\
\hline Authority $(0.708)$ & That the author/organisation is known to me & AUI & & 4.14 & 1.01 \\
\hline The standing of the & That the author appears to be knowledgeable & $\mathrm{AU} 2$ & & 3.54 & 1.20 \\
\hline $\begin{array}{l}\text { author or } \\
\text { organisation }\end{array}$ & $\begin{array}{l}\text { That the author/org responsible for the information can be } \\
\text { easily identified }\end{array}$ & AU3 & 3.82 & 3.74 & 1.00 \\
\hline responsible for & That the information appears to be objective & AU4 & & 3.99 & 0.99 \\
\hline $\begin{array}{l}\text { providing the } \\
\text { information }\end{array}$ & $\begin{array}{l}\text { That the author's qualifications and/or expertise are } \\
\text { indicated }\end{array}$ & AU5 & & 3.71 & 1.16 \\
\hline
\end{tabular}

Construct adapted from: Fogg et al. [46]; Sillence, Briggs, Fishwick and Harris [14]; Metzger [2I]; Walraven, Brand-Gruwel and Boshuizen [4I]; Hargittai, Fullerton, Menchen-Trevino and Yates Thomas [34].

\begin{tabular}{|c|c|c|c|c|c|}
\hline \multirow{5}{*}{$\begin{array}{l}\text { Style }(0.756) \\
\text { The way in which the } \\
\text { information is } \\
\text { presented and written }\end{array}$} & The ease with which I can understand the information & STI & & 4.21 & 0.90 \\
\hline & The clarity of the structure of the information & ST2 & & 4.24 & 0.85 \\
\hline & The ease with which I can read the information & ST3 & 3.87 & 4.02 & 0.89 \\
\hline & The quality of the presentation of the information & ST4 & & 3.79 & 0.99 \\
\hline & The presence of a table of contents & ST6 & & 3.09 & 1.18 \\
\hline
\end{tabular}

Construct adapted from Fogg et al. [46]; Wang and Emurian [17]; Metzger [2I]; Sillence, Briggs, Harris and Fishwick [15]; Walraven, Brand-Gruwel and Boshuizen [4I]

\begin{tabular}{|c|c|c|c|c|c|}
\hline Content $(0.778)$ & The currency of the information & $\mathrm{COI}$ & & 3.70 & 0.97 \\
\hline Core characteristics & The reliability of the information & $\mathrm{CO} 2$ & & 3.90 & 0.83 \\
\hline of the information, & The comprehensiveness of the information & $\mathrm{CO} 3$ & 4.03 & 4.42 & 0.85 \\
\hline such as reliability and & The accuracy of the information & $\mathrm{CO} 4$ & & 4.32 & 0.94 \\
\hline accuracy & Mention of recent developments in treatment & $\mathrm{CO} 6$ & & 3.80 & 0.93 \\
\hline
\end{tabular}

Construct adapted from Fogg et al. [46]; Metzger [2I]; Walraven, Brand-Gruwel and Boshuizen [4I]; Hargittai, Fullerton, MenchenTrevino and Yates Thomas [34]

\begin{tabular}{|c|c|c|c|c|c|}
\hline Usefulness (0.782) & That the information tells me most of what I need to know & UFI & & 4.49 & 0.68 \\
\hline The extent to which & That the information helps me to understand the issue & UF2 & & 4.42 & 0.72 \\
\hline the user is informed & better & & 3.80 & & \\
\hline by and can make use & That I have not found similar information before & UF3 & & 3.22 & 1.02 \\
\hline of the information & That I find the information interesting & UF4 & & 3.43 & I.II \\
\hline
\end{tabular}


Whether the article gives me information that I can use Whether the article adds to my previous knowledge Whether the information seems to be tailored to me personally

The advice seemed to be offered in my best interest

The extent to which I felt that the information helped me
UF5

UF6

UF7

UF8

UF9
3.70

4.09

3.08

3.75

4.05

0.92

0.84

Construct adapted from Fogg et al. [46]

The information source (e.g. website) carries advertising

BRI

BR2

3.54

1.16

The information source carries the logo of a well-known

Brand brand

(0.797)

The information source brand has a good reputation

The information is on the website of a specialist health

BR4

BR5

0.92

0.83

1.08 charity
$3.46 \quad 1.14$

3.59

$3.45 \quad 1.10$
$3.90 \quad 1.01$

Construct adapted from Fogg et al. [46] ; Sillence, Briggs, Harris and Fishwick [15]; Walraven, Brand-Gruwel and Boshuizen [4I]; Hargittai, Fullerton, Menchen-Trevino and Yates Thomas [34]

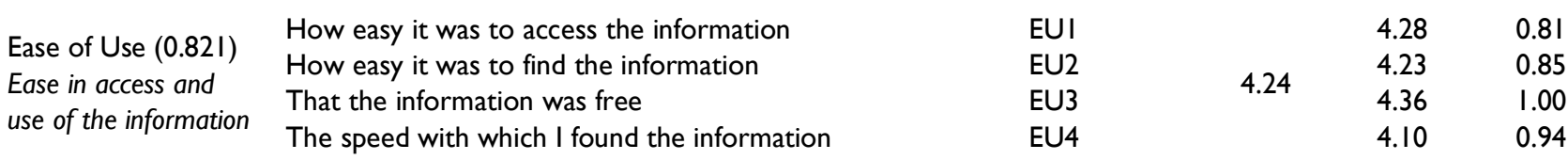

\section{Construct adapted from Metzger [2I]}

\section{Recommendation}

(0.838)

Recommendations regarding the information from known person
Family and friends have recommended the source to me A health professional has recommended the source to me I have seen online recommendations from users of the source

I have seen recommendations from a social network community

I have been advised against using a certain source

My friends and family use the source

$\begin{array}{llll}\text { REI } & & 3.24 & 1.22 \\ \text { RE2 } & & 3.93 & 1.14 \\ \text { RE3 } & & 3.33 & 1.06 \\ \text { RE4 } & 3.93 & & \\ & & 2.96 & 1.09 \\ \text { RE5 } & & 3.50 & 1.12 \\ \text { RE6 } & & 3.40 & 1.13\end{array}$

Construct adapted from Kelton, Fleischman and Wallace [6]; Rieh and Hillgoss [30];Hargittai, Fullerton, Menchen-Trevino and Yates Thomas [34]; Lim and Simon [36]

\begin{tabular}{|c|c|c|c|c|c|}
\hline \multirow{5}{*}{$\begin{array}{l}\text { Credibility } \\
(0.845)\end{array}$} & Whether I feel I can believe the information & CRI & & 4.42 & 0.75 \\
\hline & The objectivity of the information & CR2 & & 4.16 & 0.81 \\
\hline & The impartiality of the information & CR3 & 4.27 & 4.01 & 0.88 \\
\hline & The quality of the information & CR4 & & 4.40 & 0.76 \\
\hline & The extent to which contains facts rather than opinions & CR5 & & 4.34 & 0.86 \\
\hline
\end{tabular}

Construct adapted from Sillence, Briggs, Harris and Fishwick [15]; Menchen-Trevino and Hargittai [44]; Lim and Simon [36]

$\begin{array}{lllrr} & \text { The inclusion of references to related sources } & \text { TRI } & 3.82 & 1.04 \\ \text { Triangulation } & \text { Hyperlinks through to other web pages and documents } & \text { TR2 } & 3.77 & 3.44 \\ \text { (0.705) } & \text { Consistency with information that I have found elsewhere } & \text { TR3 } & 4.02 & 0.91 \\ & \text { Consistency with my prior knowledge } & \text { TR4 } & 3.79 & 0.94\end{array}$

Construct adapted from Wang and Emurian [17]; Metzger [2I]; Rieh and Hillgoss [30]; Hargittai, Fullerton, Menchen-Trevino and Yates Thomas [34]; Menchen-Trevino and Hargittai [44]; Lim and Simon [36]

\begin{tabular}{|c|c|c|c|c|c|}
\hline & My familiarity with the topic & FAI & & 3.58 & 0.99 \\
\hline \multirow[t]{2}{*}{$\begin{array}{l}\text { Familiarity } \\
(0.744)\end{array}$} & $\begin{array}{l}\text { Previous positive experience with info. from the same } \\
\text { source }\end{array}$ & FA2 & 3.64 & 3.76 & 0.94 \\
\hline & Whether the information is on my favourite health web- & FA3 & & 3.32 & 1.16 \\
\hline
\end{tabular}


site

My confidence that I will understand information that I find FA4

$3.89 \quad 0.96$

Construct adapted from Lucassen T and Schraagen JM [20]

In order to verify the trust inventory in the questionnaire, factor analysis with principal component analysis (PCA) was used to analyse the relationships among the items and where these converge, to identify and extract the underlying factors in the participants' responses. Based on items used in previous research, the trust scale to identify the likely factors influencing trust is shown in Table 2. The extracted factors from PCA are re-labelled according to the items that have converged in the analysis, as effectively measuring a common underlying or latent construct. These derived factors are presented in Table 4 labelled to reflect the propositions that these are characteristics and attributes of the information used in the process of assessing trustworthiness. Prior to conducting PCA the suitability of the data for this test was established. The KMO value was 0.874 , which is greater than the recommended value of 0.6 . Bartlett's test was test is statistically significant with a value of .000 level. Furthermore if the questions (items) for a construct are well designed they should converge and form a major factor (Hair et al. [46]). The major principle components (with eigenvalue greater than1) were extracted as constructs and to satisfy convergent validity, that all items intended to measure a construct do reflect that construct, the factor loadings were greater than 0.5 . Items with low loading or cross loading were removed as follows: CO1, CO6, AU1, AU2, ST6, TR4, UF5, UF9. The principal components extracted suggest a good fit of 35 items to seven latent constructs accounting for $53.6 \%$ of total variance. Table 3 lists the eigenvalues associated with these seven factors, and the variance in the evaluation process associated with trust judgements explained by each of the factors. Specifically, factor 1 explains $25.0 \%$ of the total variance, factor $2(7.7 \%)$, factor 3 $(6.1 \%)$, factor $4(4.4 \%)$, factor $5(3.7 \%)$, factor $6(3.5 \%)$ and factor $7(3.1 \%)$. These were labelled follows, factors 1 (Reliable Content), 2 (Assessing Credibility), 3 (Personal Recommendation), 4 (Ease of Use- Access), 5 (Assessing Usefulness), 6 (Style - Readable) and 7 (Branded - Logo). Thus 'Reliable Content' with items relating to the authorial authority and to the comprehensiveness and accuracy of the information accounted for the greatest total variance. Two factors were not formed on the survey items and these were intended to measure triangulation/verification and familiarity. As this is explained by the method adopted for data collection it is discussed in concluding section of the paper.

Table 3: Variance explained by each of the factors for trust.

\begin{tabular}{|c|c|c|c|c|c|c|c|c|c|}
\hline \multirow[b]{2}{*}{ Component } & \multicolumn{3}{|c|}{$\begin{array}{l}\text { Initial Eigenvalues } \\
\quad \% \text { of }\end{array}$} & \multicolumn{3}{|c|}{$\begin{array}{l}\text { Extraction Sums of Squared Loadings } \\
\qquad \% \text { of }\end{array}$} & \multicolumn{3}{|c|}{$\begin{array}{c}\text { Rotation Sums of Squared Loadings } \\
\% \text { of }\end{array}$} \\
\hline & Total & Variance & Cumulative\% & Total & Variance & Cumulative \% & Total & Variance & Cumulative\% \\
\hline $\mathrm{I}$ & 12.51 & 25.02 & 25.02 & 12.51 & 25.02 & 25.02 & 4.64 & 9.27 & 9.27 \\
\hline 2 & 3.87 & 7.74 & 32.76 & 3.87 & 7.74 & 32.76 & 3.60 & 7.20 & 16.47 \\
\hline 3 & 3.05 & 6.11 & 38.87 & 3.05 & 6.19 & 38.87 & 3.50 & 7.00 & 23.47 \\
\hline 4 & 2.22 & 4.45 & 43.31 & 2.22 & 4.45 & 43.31 & 3.25 & 6.51 & 29.97 \\
\hline 5 & $\mathrm{I} .87$ & 3.74 & 47.06 & 1.87 & 3.74 & 47.06 & 2.85 & 5.71 & 35.68 \\
\hline 6 & I.74 & 3.48 & 50.54 & I.74 & 3.48 & 50.54 & 2.74 & 5.47 & 41.15 \\
\hline 7 & I.54 & 3.09 & 53.62 & $\mathrm{I} .54$ & 3.09 & 53.62 & 2.69 & 5.37 & 46.52 \\
\hline
\end{tabular}


Table 4: Convergent validity of the measurement model.

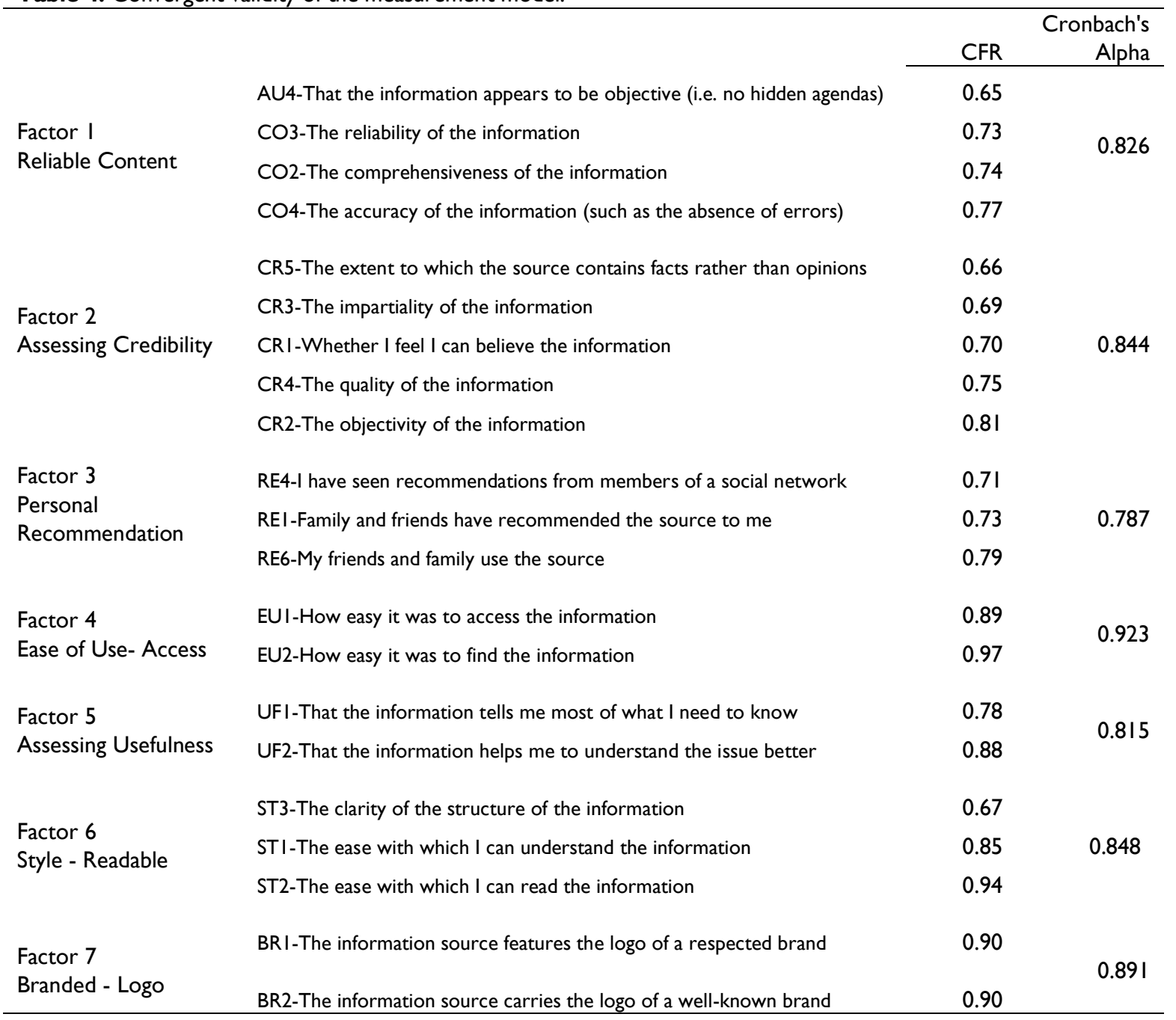

The results from the PCA suggest a good fit of items to latent constructs To further determine the items as attributable to a factor, Confirmatory Factor Analysis (CFA) was used to test the factor structure extracted and ensure instrument quality, prior to its use in structural equation modelling. According to Segars and Grover [44], the measurement model should be evaluated first and then re-specified as necessary to generate the 'best-fit' model. Therefore the pre-specified construct-item correspondences must be significant with composite factor reliability (CFR) $>0.7$ and Cronbach's alpha $>0.5$ (Hair et al. [47]) and with the construct explaining more than 50\% of the total variance (with the average variance extracted (AVE) for an item $>0.5$ ). This process led to a refined measurement model with seven factors and twenty one items (Table 4). Item reliability ranged from 0.65 to 0.97 , thus exceeding the acceptable value of 0.5 . Composite reliability for these seven factors ranged from 0.761 to 0.926 , which is above the 0.7 . Finally, the average variance extracted ranged from 0.516 to 0.805 , and for all items exceeded the threshold value of 0.5 recommended by Fornell and Larcker [49]. Together these indices show that the model has an appropriate level of reliability, convergent validity, and determinant validity.

\subsection{Structural relationships among the factors}

When all constructs are measured with multiple questions in the survey, and the 'latent meaning' extracted, the proposed relationships between the independent (e.g., Style - Readable and Personal Recommendation) and the dependent (i.e. Assessing Credibility and Assessing Usefulness) can be tested. Structural equation modelling in AMOS 
specifies both item-construct correspondence and construct - construct causal relationships. If the hypotheses are supported we expect significant regression coefficients when they are solved with maximum likelihood estimation. This procedure of structural equation modelling was followed for the relationship between Assessing Usefulness and Credibility and the other variables.

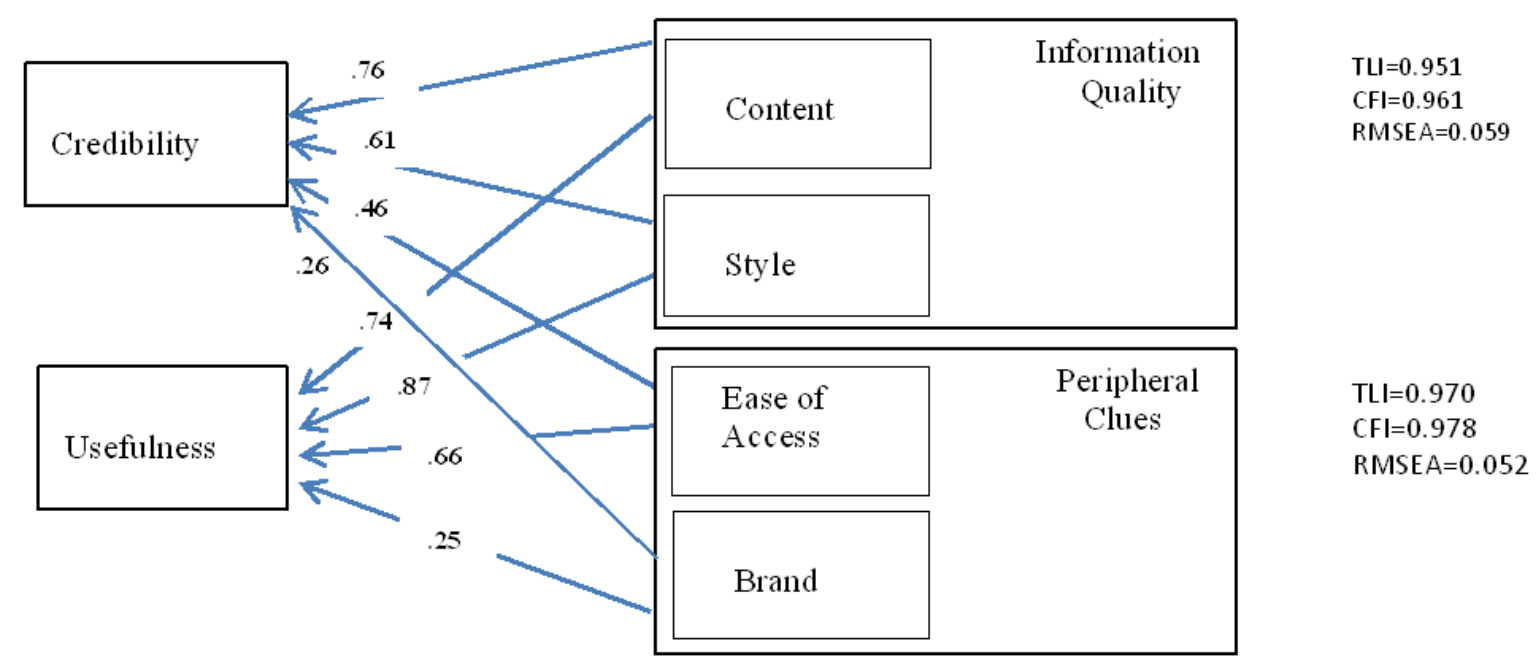

Figure I. Trust formation by core criteria (Assessing Credibility and Usefulness) determined by Information Quality and Peripheral factors.

The fit of the data model can be shown with the root mean square error of approximation (RMSEA) less than 0.10 at 0.059 and 0.052 , the goodness of fit index (GFI) greater than 0.9 at 0.961 and 0.978 . The model would seem to support the propositions that Assessing Usefulness and Assessing Credibility are criteria in a (formation of) trust judgement and are determined by factors relating to document properties or contextual influences. The factor Assessing Usefulness held strongest associations with Style - Readable (.87), Reliable Content (.74).Ease of Use - Access (.66) and Assessing Credibility with Reliable Content (.76), Style - Readable(.61) and to lesser extent Ease of Use - Access (.46). Branded Logo held a weak association with both Assessing Credibility and Usefulness. The regression for the factor labelled Personal Recommendation was not significant nor obtained on either the dependent factors of Assessing Credibility or Usefulness.

\subsection{Relationships among the factors}

The conceptualisation of trust formation presented in this study stems, in the main, from the recognition that trust in digital information is formed in a dependency state and, as such, the judgements made on criteria, such as usefulness or credibility, may depend on the context, particularly user or task characteristics. To illustrate the potential use of the model of trust formation, as a framework for such further investigation, a regression analysis was run on each of the factors that influence Assessing Usefulness and Credibility. With the intention to gain insight into the dependency of the judgements, this analysis was carried out on the data from participants who reported a high involvement and from those who reported a low involvement in the health information. In these two contexts it may be assumed that the different levels of involvement, or invested interest in the information, will have some impact on the assessment of trustworthiness. Significant regression coefficients were obtained on Assessing Usefulness and Assessing Credibility with the factors Reliable Content, Style-Readable, Ease of Use - Access and Branded- Logo when run across participants data with HIGH level involvement and participants with LOW level of involvement (With HIGH level of involvement with the factors accounted for $50 \%$ of variance in Usefulness ( $\mathrm{p}=.000 \mathrm{df}=42$, anova $=12.821, \mathrm{~F} 9.612)$ and $37.6 \%$ on Credibility $(\mathrm{p}=.001, \mathrm{df}=42$, anova $=18.663, \mathrm{~F} 5.736)$. With a LOW level involvement the predictors accounted for $43 \%$ of variance in Usefulness $(\mathrm{p}=.000, \mathrm{df}=234$, anova $=71.033, \mathrm{~F} 43.33)$ and $34.5 \%$ on Credibility $(\mathrm{p}=.000, \mathrm{df}=237$, anova $=94.784, \mathrm{~F} 30.742$ ) ). Of particular interest, however, is the contribution of each predictor variable to the criteria (Table 5). With participant HIGH level of involvement only Style-Readable held a significant coefficient in association 
with Assessing Usefulness $(\beta=.483, p=.002)$ and only Reliable Content with Credibility (Beta $\beta=.548, p=.002)$. With a LOW level involvement the regression model for Assessing Usefulness shows each of the four factors contributing in a similar way with the coefficient associations of Reliable Content $(\beta=.238, \mathrm{p}=.000)$, Style -Readable $(\beta=.231, \mathrm{p}=.000)$, Branded - Logo $(\beta=.213, \mathrm{p}=.000)$ and Ease of Use-Access $(\beta=.201, \mathrm{p}=.001)$. On Credibility an association was held on all factors except Style - Readable with the coefficient associations of Reliable Content $(\beta=.398, p=.000)$, Branded Logo $(\beta=.127, \mathrm{p}=.029)$ and Ease of Use - Access $(\beta=.243, \mathrm{p}=.000)$. It appears that with a high involvement, trust may be formed on Assessing Usefulness and Credibility and the factors that might influence these judgements relate to the Information Quality, and in this data set these were Style - Readable with Assessing Usefulness, and Reliable Content with Assessing Credibility. With a low involvement, trust is also formed on Assessing Usefulness and Credibility and both the Information Quality and the Peripheral factors might influence these judgements, as in this data set, Reliable Content, Style - Readable, Branded -Logo and Ease of Use - Access related with Assessing Usefulness and Reliable Content, Ease of Use -Access and Branded Logo related with Assessing Credibility. Tempting as it is to conclude that a low involvement leads to the use of many and various factors in assessing information usefulness and credibility, whereas with a high involvement specific use is made of only information quality, for example Style - Readable. The analysis carried out here is for illustrative purposes to suggest that the modelling of the factors, as determinants of the core criteria in assessing trustworthiness, may be used to explore such variations in the process invoked by different task contexts.

Table 5. Coefficients for each factor to usefulness and credibility across user level of involvement/interest.

\begin{tabular}{|c|c|c|c|c|}
\hline $\begin{array}{l}\text { ASSESSING } \\
\text { USEFULNESS }\end{array}$ & Reliable Content & Style-Readable & Ease of Use-Access & Branded - Logo \\
\hline Low Involvement & $\beta=.238, p=.000 * *$ & $\beta=.231, p=.000^{*} *$ & $\beta=.201, p=.001^{*}$ & $\beta=.213, p=.000 * *$ \\
\hline High Involvement & $\beta=.215, p=.147$ & $\beta=.483, p=.002 *$ & $\beta=.129 p=.371$ & $\beta=.003, p=.981$ \\
\hline $\begin{array}{l}\text { ASSESSING } \\
\text { CREDIBILITY }\end{array}$ & Reliable Content & Style-Readable & Ease of Use-Access & Branded - Logo \\
\hline Low Involvement & $\beta=.398, p=.000 * *$ & $\beta=.016, p=.814$ & $\beta=.243, p=.000 * *$ & $\beta=.127, p=.029 *$ \\
\hline High Involvement & $\beta=.548, p=.002 *$ & $\beta=.007, p=.966$ & $\beta=.088, p=.587$ & $\beta=.053, p=.703$ \\
\hline
\end{tabular}

\section{Discussion and Conclusions}

The results of the exploratory and confirmatory factor analysis presents the seven constructs involved in the formation of trustworthiness judgement of information (in health domains). These explain 53.6\% of the variance in the data on the trust scales suggesting that these factors are quite comprehensive in explaining trust judgements. The premise was that the relationship held between these constructs of trust would be such that the criteria as antecedents to trust formation are determined by the independent variables of the document properties (or perceptions of) and /or by other peripheral factors. The results show that the constructs of content, style and ease of access are most strongly associated with the constructs of assessing credibility and usefulness. Thus, assessing credibility and usefulness, when considered as key antecedents to trust formation, may be influenced by both information content and style and by peripheral factors such as ease of use. Previously, Sillence et al. [15] divided the factors contributing to the selection and trust of web sites into content factors, such as informative content and into design factors, such as good navigation aids. They also recognised the judgement to be dynamic, as do others such as Lucassen and Schragen [50] suggesting that trust formation is further influenced by user characteristics (such as domain expertise) and which lead to different features of the information being used in trust judgements. Whilst this present study did not gather details on domain knowledge, a distinction was made on level of involvement in the information and, further analysis based on the model of factors influencing the judgements of usefulness and credibility, indicated variation in the peripheral and the factors relating to information quality in assessing trustworthiness. Related research on the dependency role of the task context, for example user domain knowledge, has focused the impact on query attributes, search strategies and tactics, and search outcomes (White et al. [53]) and as determinants of the users' ability to find useful information (Wildemuth [51], Hembrooke et al., [52]). For example, in relation to online health information Keselman et al. [54], found that imprecise domain knowledge led consumers to search for information on irrelevant sites. Focusing more on the user's evaluation of the information, Lucassen and Schraagen's [50] study of Wikipedia use did show that those familiar with a topic focussed on the semantic features of the information, whilst those who were unfamiliar with the topic paid more attention to 
surface features. The Elaboration Likelihood Model (ELM) possibly goes some of the way to explaining this in suggesting that user characteristics, such as motivation, explains the different use of content and peripheral cues in credibility assessment. Both Cacioppo and Petty [32] and Sundar [31] have suggested that individuals may base their judgement of a message, not on its content but, on peripheral cues when the motivation to engage in the mental effort in analysing a message based on content is missing or lacking. In this present study it appears that, with a passing interest in the information, both the factors relating to information quality and those which may be regarded as peripheral to content were used in the judgements of information usefulness and credibility; whereas when the investment or interest in the information is high, the factors relating to information quality had more influence on the user judgements.

The results of this study with the core criteria of trust, assessing usefulness and credibility, variously influenced by the content and peripheral factors suggests that whilst the judgements are formed as antecedents to trust, their influences may vary with different factors used to form these judgements. In modelling trust formation in this way it is possible to allow for the fact that, regardless of the user context, trust will be formed based on an evaluation of the information usefulness and credibility, however the influence of various factors on these will vary according to the user context, in other words the dependency state in which trust is formed.

\section{I. Limitations}

The model is incomplete as the constructs of familiarity and triangulation/verification were removed from the model of factors in trust formation. The consequence is that important dimensions to the 'trust model' may have been omitted, but are accounted for in the explanation that they were not adequately observed in the questionnaire setting. In the propositions on trust these and other peripheral (i.e., not content based) clues could predict or influence trust formation. However our respondents were, more than likely, challenged to respond to these items in the survey. The proposition on the impact of the peripheral clues on assessing trustworthiness requires data collection during the users searching for the information in question or immediately after. Whilst this hindered our ability to investigate the peripheral clues, it is notable that a 'peripheral' factor, Ease of Use -Access was found to hold a relation with the criteria of trust, especially Assessing Usefulness. To strengthen the model the data collection may be better carried out 'in situ' particularly to investigate the rating on the criteria of 'assessing usefulness' and the influence of the 'peripheral' factors in making this judgement. Whilst the usefulness construct was measured on the two items, UF 1 and UF2 (the information tells me most of what I need to know, and the information helps me to understand the issue better) when conducted in the immediate context of finding the information some of the items relating to the informativeness of the information, such as UF 4 (I find the information interesting) or UF9 (The extent to which I felt that the information helped me) might converge in the Assessing Usefulness factor. In the limitations of the survey the decision was made to delete these items and the factors of verification/triangulation and familiarity.

\subsection{Trust revisited}

The aim of this study was to identify the core criteria and influencing factors in assessing the trustworthiness of digital information. The guiding framework was to define trust formation based on the assessment of trustworthiness in a dependency state and on key criteria employed in the critical evaluation of information and evidenced by a set of factors. The key propositions presented are that the judgements of usefulness and credibility are core to trust formation. Whilst trust itself may be intangible, these judgements of usefulness and credibility are measurable and can be treated as the dependent variables, that is, the judgements of the information that are essential in trust formation. This framework also allows the important distinction between the judgements in trust formation and the factors or constructs on which these judgements are based, and furthermore, the distinction is made between the influencing factors that are information attributes and those that are peripheral such as ease of access, brand and recommendation Whilst previous studies have speculated on the influence of all these factors in conceptualising trust, adopting a psychometric procedure for the analysis of the questionnaire in this study enabled the modelling of the relations held among the constructs of trust being Assessing information Usefulness, Assessing information Credibility, Reliable Content, Style - Readable, Ease of Use -Access and Branded - Logo. There is scope, however, to collect further data on the assessment of trustworthiness when interacting with specific information to model possible further constructs of trust. Furthermore, in order to establish the extent to which the findings of this study are reflective of a generalised model of trust formation, further research would be required across domains other than health information. However, the contribution made in disentangling the factors influencing trust lies in the possible opening up of the investigation into trust formation in and 
across various contexts where the influences may have varying importance in the critical assessment of trustworthiness leading to intention to use.

\section{References}

[1] Kohn M. Trust: self interest and the common good. Oxford University Press, 2008.

[2] Chopra K and Wallace WA. Trust in electronic environments. .System Sciences, 2003. Proceedings of the 36th Annual Hawaii International Conference on. IEEE, 2003.

[3] Shekorpour S and Ketebi SD. Modeling and evaluation of trust with an extension in semantic web. Web Semantics: Science and Agents on the World Wide Web 2010, 8(1) 20 26-36.

[4] Yi MY, Yoon JJ, Davis, JM and Lee T. Untangling the antecedents of initial trust in Web-based health information: The roles of argument quality, source expertise, and user perceptions of information quality and risk. Decision Support Systems 2013, 55(10) 284-295.

[5] Ivanov I, Vajda P, Lee JS and Ebrahimi T. In tags we trust: Trust modeling in social tagging of multimedia content. Signal Processing Magazine 2012, IEEE 29(2).

[6] Kelton K, Fleischman KR and Wallace WA. Trust in digital information. Journal of the American Society for Information Science and Technology, 2008, 59 (3), 363-374.

[7] Belanger F and Carter L. Trust and risk in e-government adoption. The Journal of Strategic Information Systems 2008, 17(2), 165-176.

[8] Rotter JB. Interpersonal trust, trustworthiness, and gullibility.American Psychologist 1980, 35.1.

[9] Hardin R. Trust and trustworthiness. 4. Russell Sage Foundation, 2004.

[10] Rowley J and Johnson F. Understanding trust formation in digital information sources: The case of Wikipedia. Journal of Information Science 2013, 39(4), 494-508.

[11] Goudge J and Gilson L. How can trust be investigated? Drawing lessons from past experience. Social Science \& Medicine 2005, 61(7), 1439-1451.

[12] Corritore C, Wiedenbeck S, Kracher B. and Marble RP. Online Trust and Health Information Websites. International Journal of Technology and Human Interaction 2012, 8(4), 92-115.

[13] Ye Y. Correlates of consumer trust in online health information: findings from the Health Information National Trends Survey. Journal of Health Communication 2011, 16 (1), 34-49.

[14] Sillence E, Briggs P, Fishwick L, and Harris P. Trust and mistrust of online health sites. In: Proceedings of CHI 204. ACM Press 2004, 663-670.

[15] Sillence E, Briggs P, Harris P, and Fishwick L. How do patients evaluate and make use of online health information? Social Science \& Medicine 2007, 64, 1853-1862.

[16] Mechanic D and Meyer A. Concepts of trust among patients with serious illness. Social science \& medicine, 2000,51(5), 657-668.

[17] Wang YD and Emurian HH. An overview of online trust: concepts, elements, and implications. Computers in Human Behaviour 2005, 21, 105-125.

[18] Briggs P, Burford B, De Angeli A and Lynch P. Trust in online advice. Social Science Computer Review 2002, 20(3), 321-332.

[19] O Neill O. A question of trust: the BBC Reith Lectures, 2002. Cambridge University Press, 2002.

[20] Lucassen T and Schraagen JM. Factual accuracy and trust in information: the role of expertise. Journal of the American Society for Information Science and Technology 2011, 62 (7), 1232-1242.

[21] Metzger MJ. Making sense of credibility on the Web: models for evaluating online information and recommendations for future research. Journal of the American Society for Information Science and Technology 2007, 58 (13), 2078-2091.

[22] Wathen CN and Burkell J. Believe it or not: factors influencing credibility on the web. Journal of the American Society for Information Science and Technology 2002, 53(2), 134-144.

[23] Cugelman B, Thelwall M and Dawes P. The Dimensions of we site credibility and their relation to active trust and behavioural impact. Communications of the ACM 2009, Article 26, 455-472.

[24] Shen X-L, Cheung CM and Lee MKO. What leads students to adopt information from Wikipedia? An empirical investigation into the role of trust and information usefulness. British Journal of Educational Technology 2012 , 44(3), 502-517.

[25] Harris PR, Sillence E and Briggs P. Perceived threat and corroboration: key factors that improve a predictive model of trust in Internet-based health information and advice. Journal of Medical Internet Research 2011,13 (3).

[26] Fergie G, Hunt K and Hilton S. What young people want from health-related online resources: a focus groups study. Journal of Youth Studies 2013, 16, 579-596.

[27] Sillence E, Briggs P, Harris P and Fishwick, L. Going online for health advice: changes in usage and trust practices over the last five years. Interacting with Computers 2007, 19, 397-406. 
[28] Saracevic T. Relevance: A review and a framework for the thinking on the notion in information science, Journal of the American Society for Information Science and Technology 1975, 26(6), 321-343.

[29] Borlund P. The concept of relevance in IR. Journal of the American Society for Information Science and Technology 2003, 54(10), 913-925.

[30] Rieh SY and Hilligoss B. College students' credibility judgements in the information seeking process. In: Digital Media, Youth and Credibility edited by M J Metzger. Cambridge, MA: MIT Press, 2008 pp. 49-71.

[31] Sundar SS. The MAIN model: A heuristic approach to understanding technology effects on credibility.Digital media, youth, and credibility 2008, 73-100.

[32] Cacioppo JT and Petty RE. The elaboration likelihood model of persuasion. Advances in Consumer Research 1984 11(1).

[33] Tseng S and Fogg BJ. Credibility and computing technology. Communications of the ACM. 1999, 42 (5), 39-44

[34] Hargittai E, Fullerton L, Menchen-Trevino E and Yates Thomas K. Trust online: young adults' evaluation of web content. International Journal of Communication 2010, 4, 468-494.

[35] Shankar V, Urban GL and Sultan F. Online trust: a stakeholder perspective, concepts, implications, and future directions. Strategic Information Systems 2002, 11, 325-344.

[36] Lim S. How and why do college students use Wikipedia? Journal of the American Society for Information Science and Technology 2009, 60 (11), 2189-2202.

[37] Hertzum M, Andersen HHK, Andersen V and Hansen CB. Trust in information sources: seeking information from people, documents, and virtual agents. Interacting with Computers 2002, 14, 575-599.

[38] Pan B, Hembrooke H, Joachims T, Lorigo L, Gay G and Granka L. In Google we trust: users' decisions on rank, position and relevance. Journal of computer-mediated communication 2007, $12,801-823$.

[39] Bailey P, Thomas P and Hawking D. Does brand name influence perceived search result quality? Yahoo!, Google, and Web. Proceedings of ADCS 2007.

[40] Iding MK, Crosby ME, Auerheimer B and Klemm EB. Web site credibility: why do people believe what they believe? Instructional Science 2009, 37 (1), 43-63.

[41] Walraven A, Brand-Gruwel S and Boshuizen HPA. How students evaluate information and sources when searching the World Wide Web for information. Computers \& Education 2009, 52(1), 234-246.

[42] Dobransky K and Hargittai E. Inquiring minds acquiring wellness: Uses of online and offline sources for health information. Health Communication 2012, 27(4), 331-343.

[43] Gray NJ, Klein JD, Noyce PR, Sesselberh TS and Cantrill JA. Health information-seeking behaviour in adolescence: The place of the Internet. Social Science \& Medicine 2005, 60(7), 1467-1678.

[44] Menchen-Trevino E and Hargittai E. Young adults' credibility assessment of Wikipedia. Information, Communication \& Society 2011, 14(1), 24-51.

[45] DeVellis RF. Scale development: Theory and Applications. (2nd Ed.), Thousand Oaks, California: Sage 2003.

[46] Fogg BJ, Marshall J, Laraki O, Osipovich A, Varma C and Fang N. What makes web sites credible? A report on a large quantitative study. Proceedings of CHI '01 Human factors in Computing Systems 2001, pp61-68

[47] Hair JF, Tatham RL, Anderson RE and Black W. Multivariate Data Analysis. 5th Ed. Prentice Hall, 1998.

[48] Segars AH and Grover V. Strategic Information Systems Planning Success: An Investigation of the Construct and Its Measurement. MIS Quarterly 1998, 22(2), 139-163.

[49] Fornell C and Larcker DF. Evaluating structural equation models with unobservable variables and measurement error. Journal of Marketing Research 1981, 18, 39-50.

[50] Lucassen T and Schraagen JM. Topic familiarity and information skills in online credibility evaluation. Journal of the American Society for Information Science and Technology 2013,64, 254-264.

[51] Wildemuth BM. The effects of domain knowledge on search tactic formulation. Journal of the American Society for Information Science and Technology 2004, 55(3), 246-258.

[52] Hembrooke HA, Gay GK and Granka LA. The effects of expertise and feedback on search term selection and subsequent learning. Journal of the American Society for Information Science 2005, 56 (8), 861-871.

[53] White RW, Dumais ST and Teevan J. Characterizing the influence of domain expertise on web search behaviour. Proceedings of WSDM, February 9-12, Barcelona, Spain,2009 pp. 132-141.

[54] Keselman A, Browne AC and Kaufman DR. Consumer health information seeking as hypothesis testing. Journal of the American Medical Informatics Association 2008, 15(4), 484-495. 